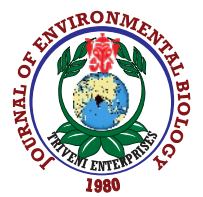

\title{
Evaluation of chickpea (Cicer arietinum L.) accessions for Fusarium wilt resistance
}

\author{
A.K. Srivastava ${ }^{1 *}$, G.P. Dixit', N.P. Singh ${ }^{2}$, D.R. Saxena ${ }^{3}$, P.R. Saabale ${ }^{4}$, K.S. Raghuvanshi ${ }^{5}$ and V.P. Anandani ${ }^{6}$ \\ ${ }^{1}$ Department of Plant Breeding, ICAR-Indian Institute of Pulses Research, Kanpur - 208 024, India \\ ${ }^{2}$ Department of Plant Biotechnology, ICAR-Indian Institute of Pulses Research, Kanpur - 208024 , India \\ ${ }^{3}$ Rajmata Vijayaraje Scindia Krishi Vishwa Vidyalaya, RAK College of Agriculture, Sehore-466 001, India \\ ${ }^{4}$ Department of Plant Pathology, ICAR- IIPR Regional Research Centre cum Off Season Nursery, Dharwad-580 005, India \\ ${ }^{5}$ Department of Plant Pathology, Mahatma Phule Krishi Vidyapeeth, Rahuri-413722, India \\ ${ }^{6}$ Department of Plant Pathology, Junagadh Agricultural University, Junagadh - 362001 , India \\ *Corresponding Author Email : bhu.avinash@gmail.com
}

\begin{abstract}
Aim: The present study was conducted to evaluate chickpea breeding lines and popular varieties for Fusarium wilt resistance through multi-location field evaluation in major chickpea growing states of India.

Methodology: Forty-five chickpea accessions were evaluated for Fusarium wilt resistance in field sick plots at Kanpur, Junagadh, Sehore and Rahuri in India during 2016 and 2017. Each accession was planted in three replications in a randomized block design. The data was subjected to analysis of variance (ANOVA) for testing the significance of variation due to accessions, environments and their interaction. GGE biplots analysis were constructed from the first two principal components (PC1 and PC2) using 45 genotypes and 8 environments using statistical software R, versions 2.15.

Results: The effects of genotype, environment and $G \times E$ interaction for wilt incidence were highly significant with maximum variation caused by $\mathrm{G} \times \mathrm{E}$ interaction effect $(50.42 \%)$, followed by genotypic $(46.92 \%)$ and environmental effect $(2.24 \%)$. GGE biplot analysis revealed that Rahuri and Junagadh locations were most discriminating locations and could differentiate the wilt resistant and susceptible chickpea accession, while Kanpur was least discriminating. Junagadh was most representative followed by Sehore and Kanpur while Rahuri was least representative of the average environment. On an average, the most severe wilt incidence was observed at Junagadh, followed by Sehore, Kanpur and Rahuri over the years.

Interpretation: Elite chickpea accessions possessing high level of fusarium wilt resistant at each location can be utilized for region specific breeding. The accessions IPC

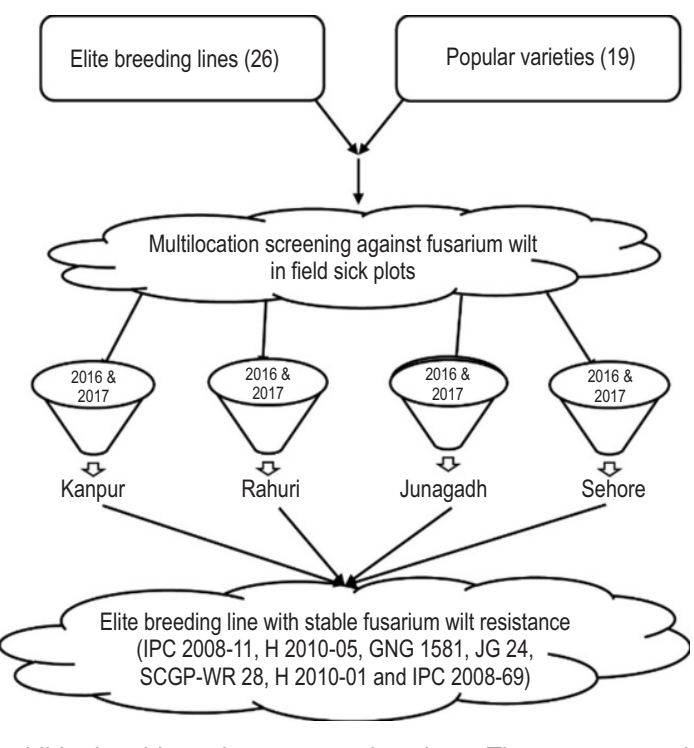
2008-11, H 2010-05, GNG 1581, JG 24, SCGP-WR 28, H 2010-01 and IPC 2008-69 exhibited stable resistance over locations. These possessed resistance against multiple races of Fusarium wilt prevailing in the country and can be utilized as donors for disease resistance breeding.
\end{abstract}

Key words: Chickpea, Fusarium wilt, GGE biplot, Multi-location evaluation, Stable resistance

How to cite : Srivastava, A.K., G.P. Dixit, N.P. Singh, D.R. Saxena, P.R. Saabale, K.S. Raghuvanshi and V.P. Anandani: Evaluation of chickpea (Cicer arietinum L.) accessions for Fusarium wilt resistance. J. Environ. Biol., 42, 82-89 (2021). 


\section{Introduction}

Chickpea (Cicer arietinum L.) has the largest share of area and production among all the pulse crops grown in India accounting for nearly 47\% (10.90 MT) of the total pulse production during 2019-20. It has shown impressive growth in the country during last few decades, still it faces many challenges hampering its production (Dixit et al., 2019). These include rainfed cultivation on poor soil, inadequate application of nutrients, narrow genetic base (Thudi et al., 2016; Srivastava et al., 2017) and various biotic and abiotic stresses affecting crop yield (Solh et al., 1994). Among biotic stresses, wilt caused by Fusarium oxysporumf. sp. ciceris is the most serious problem in all chickpea growing areas in the country (Nene et al., 2012). The average annual losses due to wilt have been estimated at about 10 to 30 $\%$, which may escalate to $90-100 \%$ (Sankad with Sunkad, 2019) depending on varietal susceptibility and climatic conditions like high soil temperature $\left(>25^{\circ} \mathrm{C}\right)$ (Cortes et al., 2000; Jimenez-Diaz et al., 2015).

Two pathotypes and eight races of pathogens have been reported across the world; among these, races $1 \mathrm{~A}, 2,3$ and 4 have been reported from India, while races $0,1 \mathrm{~A}, 1 \mathrm{~B} / \mathrm{C}, 5$, and 6 from the United States and Spain (Sharma et al., 2005). The host resistance against Fusarium wilt has been reported to be governed by single or multiple genes based on different races and resistance sources (Kumar 1998; Tullu et al., 1999; Sharma et al., 2007; Gowda et al., 2009; Singh et al., 2014). The pathogen F. oxysporum transmits through seed as well as soil (Jendoubi et al., 2017) and can survive on plant debris, weeds, etc., over years even in the absence of host plants (Castro et al., 2012). Hence, the best strategy to manage this disease is to use the resistant cultivars (Sharma et al., 2005). Progress in resistance breeding in chickpea suffers due to variation in pathogen races over different locations as well as interaction with varying weather conditions prevalent over years(Sharma et al., 2009; Soren et al., 2016).

This is further accentuated due to climate change which may increase wilt severity due to rise in soil temperature necessitating pre-emptive breeding (Imtiaz et al., 2011). Many researchers have identified elite genotypes through field screening of chickpea germplasm for resistance against Fusarium wilt (Dubey and Singh 2008; Saabale et al., 2017). These studies are mostly based on evaluation of limited germplasm at one or few locations. As such, the resistance is often limited to wilt races prevalent in particular region and the donor can be utilized for breeding programs for that region only. Hence, there is a need for country-wide mining of elite chickpea germplasm possessing stable resistance across different regions which can be readily utilized in chickpea wilt resistance breeding programmes in the country. The present study aims to screen chickpea breeding lines emanated from various chickpea breeding centres in different geographical locations across the country and popular varieties against complex races of Fusarium wilt through multi-location screening and evaluation at different wilt sick plots distributed at four diverse locations in the country.

\section{Materials and Methods}

Plant material and evaluation locations: For the present study, 45 chickpea accessions including 26 advanced breeding lines and 19 released varieties were evaluated for Fusarium wilt resistance during 2016 and 2017. The details of these 45 accessions are provided in Table 1. The screening for Fusarium wilt resistance was done in wilt sick plots located at 4 different locations in the country viz., Kanpur (Kan) in the north and Junagadh (Juna), Sehore (Seh) and Rahuri (Rah) in Central India. These locations traverse from $19^{\circ} 23^{\prime} 33^{\prime \prime}$ to $26^{\circ} 26^{\prime} 59^{\prime \prime} \mathrm{N}$ latitude and $70^{\circ} 27^{\prime} 23^{\prime \prime}$ to $80^{\circ} 19^{\prime} 54^{\prime \prime} \mathrm{E}$ longitude varying from 90 to $515 \mathrm{~m}$ above mean sea level, representing the chickpea growing belt of India.

Data collection and analysis: Each accession was planted in three replications in a randomized block design with each replication comprising of 2 rows of $4 \mathrm{~m}$ length at row and plant spacing of $30 \times 10 \mathrm{~cm}$. A highly susceptible cultivar JG-62 was included as infestor after every 2 rows of accessions under evaluation. JG-62 has been reported to be susceptible to all the races of Fusarium wilt except race 0 (Sharma et al., 2005). Race 0 has not been reported in India till date hence, the variety JG 62 qualifies as highly susceptible control against Fusarium wilt in India. Data on wilt incidence was recorded from each replication at 10 days interval during entire crop season. Cumulative percent wilt incidence at all the stages for each genotype was used for data analysis. Percentage wilt incidence of each test genotype was calculated by the following formula (Nene et al, 2012):

Fusarium Wilt incidence $(\%)=\frac{\text { Number of infected plants }}{\text { Total number of plants }} \times 100$

Reaction of test genotypes was determined by following disease rating scale of Nene et al, (2012) with little modification. Depending upon the range of wilt incidence, the test genotypes were grouped as resistant (<10.0 mortality), moderately resistant (10.1-20.0\% mortality) and susceptible (>20.0\% mortality). The data was subjected to analysis of variance (ANOVA) for testing the significance of variation due to accessions, environments and their interaction for Fusarium wilt incidence as described by Gomez and Gomez (1984). Mean values were calculated and compared using F-test at $5 \%$ level of significance. Locations (4) and years (2) were combined to form 8 diverse environments. GGE biplots analysis was performed on Fusarium wilt incidence among 45 accessions using statistical software R, versions 2.15. Biplots were constructed using 45 genotypes and 8 environments.

The GGE biplots were constructed from the first two principal components (PC1 and $\mathrm{PC} 2$ ) that were derived by subjecting mean values to singular-value decomposition (Frutos et al., 2014). For testing the mean performance and stability of an accession, the biplots were drawn using Mean vs Stability function with no scaling (Scale $=0)$, Tester Centered $G+G E$ (Centering $=2$ ) with genotype focused (Row metric preserving) 
singular-value partitioning (SVP = 1). For testing the environments, the Discrimitiveness vs Representativeness function was utilized with no scaling (Scale $=0)$, Tester Centered $\mathrm{G}+\mathrm{GE}$ (Centering = 2) with environment focused (Column metric preserving) singular-value partitioning $(\mathrm{SVP}=2)$.

\section{Results and Discussion}

ANOVA based on evaluation of chickpea genotypes at 8 diverse environments indicated significant genotypic, environmental and genotypic $x$ environment $(G \times E)$ interaction effect (Table 2). Among these three sources of variation, the $G \times E$ interaction effect showed maximum contribution towards total variation $(50.42 \%)$ followed by genotypic effect $(46.92 \%)$ and environmental effect (2.24\%). High contribution of GxE interaction indicates high level of variability in the environment i.e., variable pathogen races at different locations and effect of variation in local weather conditions over years on Fusarium wilt incidence (Kulkarni and Chopra, 1982). None of the accession showed resistant reaction against wilt at all the locations.

Table 1: Details of chickpea accessions evaluated in multi-location trial during 2016 and 2017

\begin{tabular}{|c|c|c|}
\hline Genotypes & Pedigree & Remarks \\
\hline BCP 10 & - & Breeding Line \\
\hline BCP 60 & BDNG 33 XNo. 404 XBDNG 9-3 & Breeding Line \\
\hline CSJK 96 & KAK 2 X CSJK 25 & Breeding Line \\
\hline GJG 0921 & GJG 9920 XFG 703 & Breeding Line \\
\hline GJG 1004 & GJG $0105 X$ GCP 9504 & Breeding Line \\
\hline GJG 1316 & ICCV 03112 X JAKI 9218 & Breeding Line \\
\hline GJG 1320 & ICCV 03112 X JAKI 9218 & Breeding Line \\
\hline GLK08-104 & - & Breeding Line \\
\hline GNG 2207 & C235XSAKI 9516 & Breeding Line \\
\hline GNG 2261 & GNG 1581 XPusa 1103 & Breeding Line \\
\hline GNG 2263 & GNG 1581 XAvrodhi & Breeding Line \\
\hline H 2010-01 & HC 1X GL 94022 & Breeding Line \\
\hline H2010-05 & HC 1 X GL 94022 & Breeding Line \\
\hline HK2013-109 & HK 92-94 x HK 1 & Breeding Line \\
\hline IPC 2010-134 & GNG 469 XFG 711 & Breeding Line \\
\hline IPC 2012-98 & JGK $1 \times$ JG 315 & Breeding Line \\
\hline IPC 2007-28 & DCP 92-3XJG 16 & Breeding Line \\
\hline IPC 2008-11 & DCP 92-3X GNG 469 & Breeding Line \\
\hline IPC 2008-69 & ICCV 96030 XC. Pinnatifidum & Breeding Line \\
\hline IPCK 2006-56 & (H 92-94 X HK 95-97) X HK 89-131 & Breeding Line \\
\hline JG24 & (JG $74 \times$ ICC 4958$)-21$ & Breeding Line \\
\hline JG 74315-2 & {$[\{(J G 74 \times$ WR 315) x JG 74\}-2010 -1-3-5-11-15-10-2 ] } & Breeding Line \\
\hline Phule G 12110 & ICCV 03112 XJAKI-9218 & Breeding Line \\
\hline Phule G 13107 & ICCV 03112 x JAKI 9218 & Breeding Line \\
\hline SCGPWR 28 & SAGL-109 x JG 315 & Breeding Line \\
\hline SCGPWR 32 & JG $315 \times R V S S G 2$ & Breeding Line \\
\hline BDG 128 & ICCV $2 \times \operatorname{ICCV} 5$ & Released Variety \\
\hline CSJ 515 & FG 712 XCSJ 146 & Released Variety \\
\hline DCP 92-3 & Sel. from germplasm & Released Variety \\
\hline GCP 101 & GCP 2 xICCV 2 & Released Variety \\
\hline GCP 105 & ICCL 84224 xAnnegiri 1 & Released Variety \\
\hline GNG 1581 & GPF $2 \times \mathrm{H} 82-2$ & Released Variety \\
\hline HK2 & (H 82-2 xE 100 ym.) xBhima & Released Variety \\
\hline HK4 & HK $92-94$ x HK 1 & Released Variety \\
\hline ICCV 10 & $\mathrm{PI} 231 \times \mathrm{P} 1265$ & Released Variety \\
\hline IPCK 2002-29 & $\mathrm{L} 144 \times \mathrm{H} 82-2$ & Released Variety \\
\hline IPCK 2004-29 & [(ICCV 2XICCV 88507) XICCV 42] XICC 7344 & Released Variety \\
\hline Kripa & Selection from local GP & Released Variety \\
\hline Pant G 186 & ILL 613x Pant G 114 & Released Variety \\
\hline PUSA372 & P $1231 \times P 1265$ & Released Variety \\
\hline PUSA547 & Mutant of BG 256 & Released Variety \\
\hline RSG 888 & RSG 44 xE 100ym. & Released Variety \\
\hline RSG 963 & RSG 524 xPD 84-10 & Released Variety \\
\hline Vihar & $($ ICCC $32 \times$ ICCL 8004) x (ICCC $49 \times$ FLIP 82-8C) x ICCV3) & Released Variety \\
\hline Vijay & P127xAnnegiri 1 & Released Variety \\
\hline
\end{tabular}


Table 2: Analysis of variance for Fusarium wilt incidence for 45 chickpea lines evaluated at 8 environments ( 4 locations and two years) in India

\begin{tabular}{lllll}
\hline Source of variation & d. f. & Sum of square & Mean sum of square & Variation (\%) \\
\hline Replication & 2 & 9.13 & $4.57 \mathrm{NS}$ & 2.24 \\
Environment $(\mathrm{E})$ & 7 & 13072.58 & $1867.51^{* *}$ & 46.92 \\
Genotype $(\mathrm{G})$ & 44 & 305231.56 & $6937.08^{* *}$ & 50.42 \\
Gx E & 308 & 287726.37 & $934.18^{* *}$ & \\
Error & 718 & 1857.84 & 2.59 & \\
\hline
\end{tabular}

${ }^{\text {Ns }}$ Non-significant, ${ }^{* *}$ Significant at $\mathrm{P}=0.01$

Table 3: Classification of chickpea accessions based on their resistance against Fusarium wilt at different locations

\begin{tabular}{lll}
\hline $\begin{array}{l}\text { Locations } \\
\text { with R or MR }\end{array}$ & $\begin{array}{l}\text { No. of } \\
\text { accessions }\end{array}$ & $\begin{array}{l}\text { Chickpea } \\
\text { accessions }\end{array}$ \\
\hline 8 & 8 & H 10-05, IPC 2008-11, GNG 2263, IPC 2008-69, H 10-01, JG 74315-2, JG 24, SCGPWR 28 \\
7 & 10 & IPC 07-28, CSJK 96, GNG 2261, GNG 1581, GNG 2207, SCGPWR 32, IPC 12-98, GCP 105, GJG \\
& $\begin{array}{l}\text { 1320, IPCK 06-56 } \\
6\end{array}$ & HK 4, GJG 1316, CSJ 515, GCP 101, IPC 10-134, GLK 08-104, Phule G 12110, Phule G 13107 \\
$4-5$ & 6 & BCP 60, GJG 1004, BCP 10, GJG 0921, HK 2, PG 186 \\
$1-3$ & 9 & HK 13-109, Vihar, ICCV 10, Vijay, DCP 92-3, Kripa, IPCK 04-29, PUSA 372, PUSA 547 \\
\hline
\end{tabular}

${ }^{*} \mathrm{R}$ : Resistant; MR: Moderately Resistant

However, at each location, highly resistant accessions were identified. At Kanpur, the accessions H10-05, H 10-01, GNG 263, GCP 105 and HK 4 exhibited resistant reaction. Similarly, highly resistant accessions were identified at Junagadh (BCP 10, SCGPWR 28, H 10-05, GLK 08-104, IPC 2008-11), Rahuri (CSJ 515, H 10-05, IPC 2008-11, IPC 10-134, GNG 1581) and Sehore (IPC 7-28, JG 74315-2, H 10-01, PG 186, GJG 1316). These accessions can be utilized for region specific breeding for respective states. The frequency distribution of different wilt resistant categories at each location indicated that maximum resistant accessions were reported from Junagadh, followed by Rahuri, Kanpur and Sehore (Fig.1). Maximum moderately resistant accessions were found at Kanpur, followed by Sehore, Rahuri and Junagadh. Thus, most severe wilt incidence was observed at Junagarh, followed by Sehore, Kanpur and Rahuri.

Previous reports on race distribution of Fusarium wilt in different parts of the country have indicated presence of a particular race in many locations as well as multiple races in single location. However, at each location, a predominant race was present at higher frequency (Dubey et al., 2012). This implies that a genotype having a particular race specific resistant gene will exhibit high resistance in location where Fusarium wilt race is predominant, however, the presence of other races, albeit in lesser frequency will hinder in expression of immune reaction. Further, the difference in frequency of different races alone or in combination with crop micro-climatic conditions may affect the expression of resistance of a genotype over years leading to increase or decrease in its resistance response (Sharma et al., 2009). Thus, a genotype showing high resistance in one year may become moderately resistance in other year solely due to variation in race distribution (Sharma et al., 2019) and other weather parameters like high soil temperature $\left(>25^{\circ} \mathrm{C}\right)$ and less soil moisture (Rafiq et al., 2020). The accessions $\mathrm{H} 10-05$, IPC 2008-11, GNG 2263, IPC 2008-69, H 10-01, JG 74315-2, JG 24, SCGPWR 28 exhibited moderate to high resistance against wilt at all 8 locations, while IPC 07-28, CSJK 96, GNG 2261, GNG 1581, GNG 2207, SCGPWR 32, IPC 12-98, GCP 105 , GJG 1320, IPCK 06-56 exhibited resistance at 7 locations (Table 3). These accessions showed stable resistance across locations. Other accessions showed susceptible reaction at more than one location. When genotype is tested in multi environment testing (MET) trials, shifts in relative ranking of genotype-by-environment interaction have been reported (Sharma et al., 2012; Parihar et al., 2017). Thus, GGE biplot provides a better graphical representation of true worth of an accession as it simultaneously assesses stability of genotypes, mean performance, discriminating ability, representativeness of environment, etc. (Jeberson et al., 2019).

GGE biplot was constructed by the two principle components (PC1 and PC2) derived from subjecting environment centered wilt incidence data, i.e., Fusarium wilt variation due to GGE to singular value decomposition. The first two principal components explained about $76 \%$ of total variation in multienvironment trial (Fig 2). This indicated the presence of complex interaction among genotypes and environments. The performance and stability of a genotype can be visualized graphically in GGE biplots by utilizing the average environment coordination (AEC) method (Yan, 2002). The line passing through biplot origin and marker for average environment is termed $A E C$ abcissa (AECa) and it points toward higher mean value. 


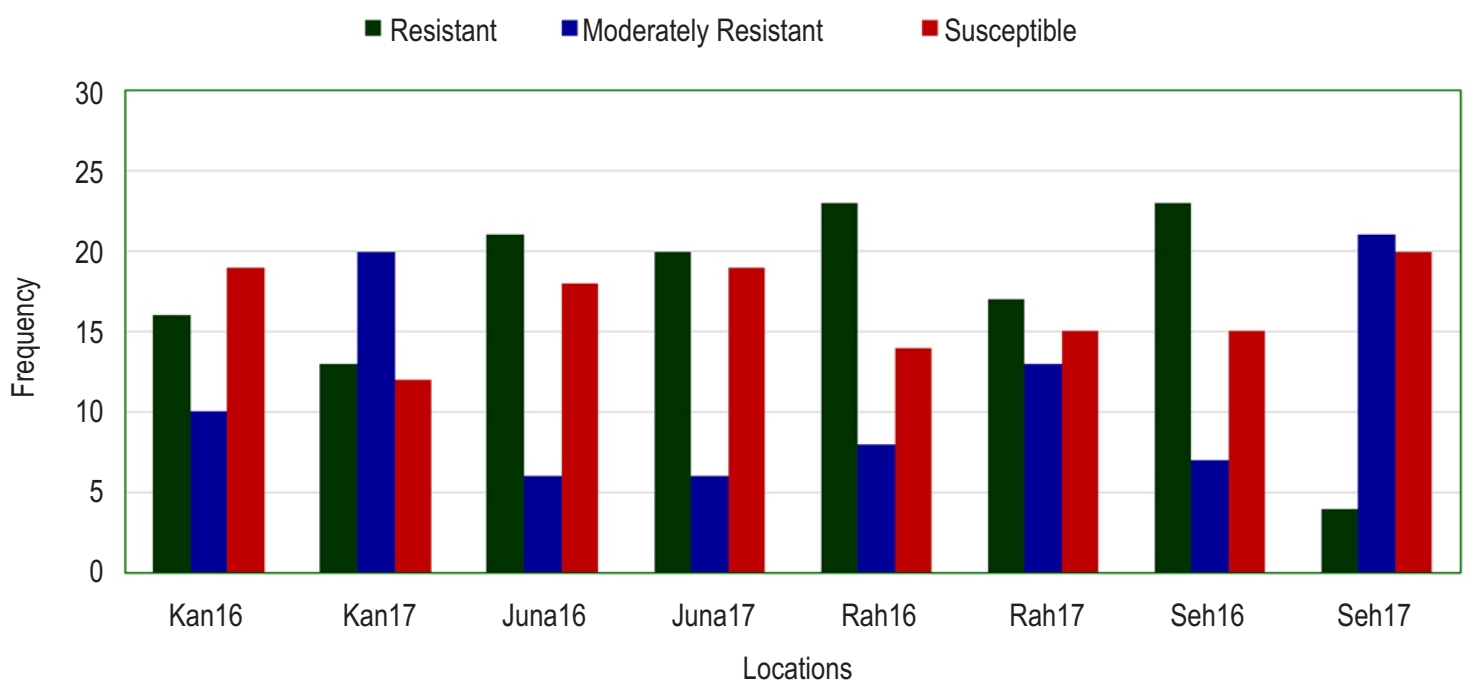

Environments: Kanpur (Kan16 \& Kan17), Junagadh (Juna16 \& Juna17), Sehore (Seh16 \& Seh17), Rahuri (Rah16 \& Rah17).

Fig. 1: Frequency distribution of 45 elite chickpea accessions based on Fusarium wilt reaction at 8 environments.

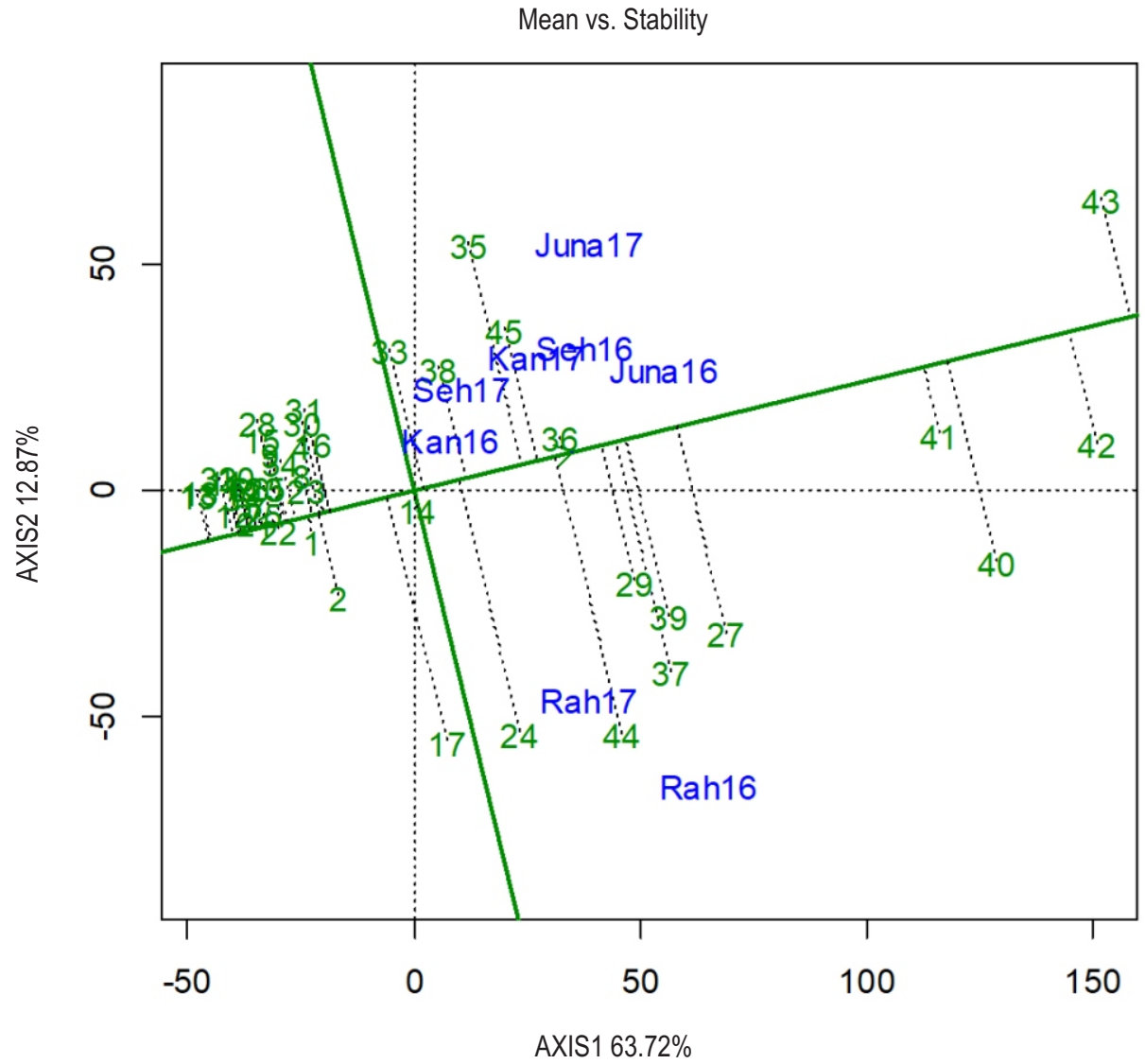

Genotypes: 1-45 as per Table 1; Environments: Kanpur (Kan16 \& Kan17), Junagadh (Juna16 \& Juna17), Sehore (Seh16 \& Seh17), Rahuri (Rah16 \& Rah17).

Fig. 2: GGE biplot based on $1^{\text {st }}$ and $2^{\text {nd }}$ Principle Components showing ranking of 45 chickpea accessions based on both mean Fusarium wilt incidence and stability over 8 environments in India. 


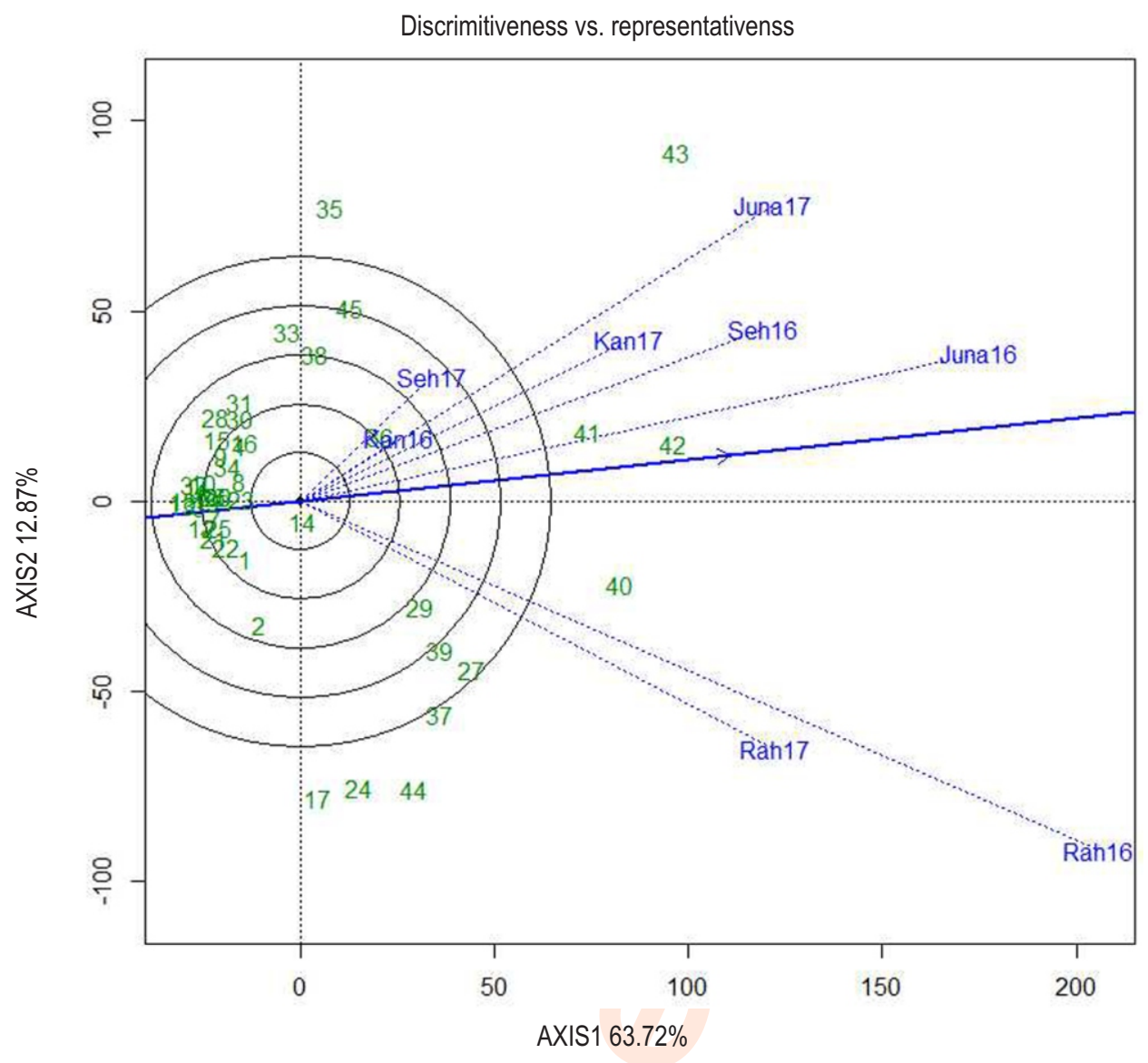

Genotypes: 1-45 as per Table 1; Environments: Kanpur (Kan16 \& Kan17), Junagadh (Juna16 \& Juna17), Sehore (Seh16 \& Seh17), Rahuri (Rah16 \& Rah17).

Fig. 3: GGE biplot based on $1^{\text {st }}$ and $2^{\text {nd }}$ Principle Component showing discriminating ability and representativeness of 8 test environments based on mean Fusarium wilt incidence of 45 chickpea accession in India.

The perpendicular line to AEC passing through the biplot origin is termed as AEC ordinates and points to greater variability (poor stability) in either direction. In the present context, the best genotypes would be having lowest wilt severity and the highest stability. Graphically, the genotype showing highly stable reaction against Fusarium wilt should show higher negative projection on $\mathrm{AECa}$ and it should be located closer to AECa, i.e., its projection on AECa should be closed to zero (Yan, 1999). Based on Mean vs Stability function of GGE biplot analysis, chickpea accession IPC 2008-11, H 2010-05,GNG 1581,JG 24 and SCGPWR 28 showed lower disease incidence with high stability (Fig. 2). Chickpea genotypes H 2010-01 and IPC 2008-69 showed moderate resistance against fusarium wilt with moderate stability.

These accessions are expected to provide stable resistance against Fusarium wilt due to presence of multiple resistance genes against different pathogen races prevalent in the northern and central parts of country (Sharma et al., 2014). These can be utilized as donors for transferring stable Fusarium wilt resistance to agronomically superior lines. In the "Discrimitiveness vs representativeness" biplot, the length of environmental vector acts as a measure of discriminating ability of an environment (Fig. 3). All the environments plotted at far distance from biplot origin indicating they all were able to discriminate between genotypes. However, they varied in their vector length, indicating difference in their discriminating ability. Thus, Rahuri (Rah16) and Junagadh (Juna16) were the most discriminating locations, while Kanpur (Kan16) was least discriminating. All the locations formed small angle with AECa and were most representative of average environment. However, Junagadh (Juna 16) was most representative followed by Sehore (Seh16) and Kanpur (Kan17), while Rahuri (Rah17) was least representative of the average environment. Test environments that are discriminative but non-representative are useful for selecting specifically adapted genotypes in target environments. Hence, Rahuri can be used to screen material having specific resistance against wilt races prevalent in the region. Nondiscriminating test environments are less useful as they provide 
less discriminating information about the genotypes. The cosine of angle between two environment vectors approximates the correlation between them. If the angle between two environment axis $<90^{\circ}$, the correlation is positive, while an angle $>90^{\circ}$ indicates negative correlation between environments. Presence of right angle between two environment axis indicates absence of correlation. All the angles between environment axis were acute $\left(<90^{\circ}\right)$, indicating positive correlation among test environments. Thus, the genotypes identified as having stable resistance against Fusarium wilt can be utilized as donors at all these test locations.

The present study provides a feasible approach to screen and identify chickpea accessions possessing resistance against multiple races of Fusarium wilt through multi-location testing. The accessions IPC 2008-11, H 2010-05, GNG 1581, JG 24, SCGPWR 28, H 2010-01 and IPC 2008-69 possessed high level of resistance against Fusarium wilt prevailing in the country. These can be utilized as donors for disease resistance breeding.

\section{Acknowledgments}

The authors acknowledge the AICRP on chickpea collaborators for sharing the data, and support from the Indian Council of Agricultural Research (ICAR), India.

\section{Add-on Information}

Authors' contribution: A.K. Srivastava, G.P. Dixit: Conceptualization, Analysis, Resources, Paper writing, Supervision; N.P. Singh: Review and finalization of paper, Supervision; D.R. Saxena, P.R. Saabale, K.S. Raghuvanshi, V.P. Anandani: Investigation, Conduct of trial, Data recording.

Research content: The research contents is original and has not been published elsewhere

Ethical approval: NotApplicable.

Conflict of interest: The author declares that there is no conflict of interest.

\section{Data from other sources: NotApplicable}

Consent to publish: All authors agree to publish the paper in Journal of Environmental Biology.

\section{References}

Castro, P., J. Rubio, T. Millán, J. Gil and M.J. Cobos: Fusarium wilt in chickpea: General aspect and molecular breeding. In: Fusarium: Epidemiology, Environmental Sources and Prevention (Eds.: T.F. Rios and E.R. Ortega). Nova Science Publishers, New York, USA, pp. 101-122 (2012)

Cortes, J.A.N., B. Hav and R.M. Jimenez-Diaz: Yield loss in chickpea in relation to development of Fusarium wilt epidemics. Phytopathology, 90, 1269-1278 (2000).

Dixit, G.P., A.K. Srivastava and N.P. Singh: Marching towards self- sufficiency in chickpea. Curr. Sci., 116, 239-242 (2019).

Dubey, S.C. and B. Singh: Evaluation of chickpea genotypes against Fusarium oxysporumf. sp. ciceris. Indian Phytopath., 61, 280-281 (2008).

Dubey, S.C., K. Priyanka, V. Singh and B. Singh: Race profiling and molecular diversity analysis of Fusarium oxysporumf. sp. ciceris causing wilt in chickpea. J. Phytopath., 160, 576-587 (2012).

Frutos, E., M.P. Galindo and V. Leiva: An interactive biplot implementation in R for modeling genotype-by-environment interaction. Stochastic Environ. Res. RiskAsse., 28,1629-1641 (2014).

Gomez, K.A. and A.A. Gomez: Statistical Procedures for Agricultural Research. John Wiley \& Sons, New York, USA(1984).

Gowda, S.J.M., P. Radhika, N.Y. Kadoo, L.B. Mhase and V.S. Gupta: Molecular mapping of wilt resistance genes in chickpea. Mole. Bree., 24, 177-183 (2009).

Imtiaz, M., R.S. Malhotra and S.S. Yadav: Genetic adjustment to changing climates: Chickpea. In: Crop Adaptation to Climate Change (Eds.: S.S. Yadav, R.J. Redden, J.L. Hatfield, H. LotzeCampen and A.E. Hall). John Wiley \& Sons Ltd, Blackwell Publishing Ltd., pp. 251-268 (2011)

Jeberson, M.S., A.K. Parihar, K.S. Shashidhar, J. Dev, S.A. Dar and S. Gupta: Identification of suitable mungbean genotypes for hilly terrains of India using GGE and AMMI biplot approaches. $J$. Environ. Biol., 40, 1188-1195(2019).

Jendoubi, W., M. Bouhadida, A. Boukteb, M. Béji and M. Kharrat: Fusarium wilt affecting chickpea crop. Agriculture, 7, 23 (2017).

Jiménez-Díaz, R.M., Pablo Castillo, María del Mar Jiménez-Gasco, Blanca B. Landa and J.A. Navas-Cortés: Fusarium wilt of chickpeas: Biology, ecology and management. Crop Protec., 73, 16-27 (2015).

Kulakarni, R.N. and V.L. Chopra: Environment as the cause of differential interaction between host cultivars and pathogenic races. Phytopathology, 72, 1384-1386 (1982).

Kumar, S.: Inheritance of resistance to Fusarium wilt (race 2) in chickpea. Plant Breeding, 117, 139-142 (1998).

Nene, Y.L., M.V. Reddy, M.P. Haware, A.M. Ghanekar, K.S. Amin, S. Pande and M. Sharma: Field diagnosis of chickpea diseases and their control. Information Bulletin No. 28. International Crops Research Institute for the Semi-Arid Tropics, Patancheru, A.P. India (2012).

Parihar, A.K., A.K. Basandrai, A. Sirari, D. Dinakaran, D. Singh, K. Kannan, K.P.S. Kushwaha, M. Adinarayan, M. Akram, T.K.S. Latha, V. Paranidharana and S. Gupta: Assessment of mungbean genotypes for durable resistance to yellow mosaic disease: Genotype x Environment interactions. Plant Breeding, 136, 94$100(2017)$

Rafiq, C.M., M.T. Mahmood, M. Ahmad, I. Ali, S. Kaukab, M. Shafiq, M. Saleem and U. Iqbal: Fusarium wilt's pathogenic studies and disease management: A review. Genet. Mol. Res., 19, gmr16039974 (2020).

Saabale, P.R., R.K. Mishra, Naimuddin and S.K. Chaturvedi: New sources of resistance in land races and advance germplasm against Fusarium oxysporum $f$. sp. ciceris race 2 causal agent of chickpea wilt. Leg. Res., 40, 364-368 (2017).

Sharma, K.D. and F.J. Muehlbauer: Fusarium wilt of chickpea: Physiological specialization, genetics of resistance and resistance gene tagging. Euphytica, 157, 1-14 (2007).

Sharma, M., A. Nagavardhini, M. Thudi, R. Ghosh, S. Pande and R.K. Varshney: Development of DArT markers and assessment of diversity in Fusarium oxysporum $f$. sp. ciceris wilt pathogen of chickpea (Cicer arietinum L.). BMC Genomics, 15, 454 (2014).

Sharma, M., R. Ghosh, A. Tarafdar, A. Rathore, D.R. Chobe, A.V. Kumar, P.M. Gaur, S. Samineni, O. Gupta, N.P. Singh, D.R. Saxena, M. 
Saifulla, M.S. Pithia, P.H. Ghante, D.M. Mahalinga, J.B. Upadhyay and P.N. Harer: Exploring the genetic cipher of chickpea (Cicer arietinum L.) through identification and multi-environment validation of resistant sources against Fusarium wilt (Fusarium oxysporum f. sp. ciceris). Front. Sust. Food Syst., 3, 78 doi: 10.3389/fsufs.2019.00078 (2019).

Sharma, M., R.K. Varshney, J. Narayan Rao, S. Kannan, D. Hoisington and S. Pande: Genetic diversity in Indian isolates of Fusarium oxysporum $f$. sp. ciceris, chickpea wilt pathogen. African J. Biotechn., 8, 1016-1023 (2009).

Sharma, M., T. Kiran Babu, P.M Gaur, R. Ghosh, T. Rameshwar, R.G. Chaudhary, J.P. Upadhyay, O. Gupta, D.R. Saxena, L. Kaur, S.C. Dubey, V.P. Anandani, P.N. Harer, A. Rathore and S. Pande: Identification and multi-environment validation of resistance to Fusarium oxysporum $f$. sp. ciceris in chickpea. Field Crops Res., $135,82-88(2012)$

Sharma. K.D., W. Chen and F.J. Muehlbauer: Genetics of chickpea resistance to five races of fusarium wilt and a concise set of race differentials for Fusarium oxysporum $\mathrm{f}$. sp. ciceris. Plant Disease, 89, 385-390 (2005)

Singh, S., I. Singh, K. Kapoor, P.M. Gaur, S.K. Chaturvedi, N.P. Singh and J.S. Sandhu: Chickpea In: Broadening the Genetic base of Grain Legumes (Eds.: M. Singh, I.S. Bisht and M. Dutta). National Bureau of Plant Genetic Resources, New Delhi, India, pp. 51-74 (2014).

Solh, M.B., H.M. Halila, G. Hernández-Bravo, B.A. Malik, M.I. Mihov and B. Sadri: Biotic and abiotic stresses constraining the productivity of cool season food legumes in different farming systems: Specific examples. In: Current Plant Science and Biotechnology in Agriculture book series (Eds.: F.J. Muehlbauer and W.J. Kaiser). Expanding the Production and Use of Cool Season Food Legumes, 19, 219-230 (1994).

Soren, K.R., P. Gangwar, P. Khatterwani, R.G. Chaudhary and S. Datta: Genetic diversity assessment of Fusarium oxysporum $f$. sp ciceris isolates of Indian chickpea fields as revealed by the SRAP marker system. J. Environ. Biol., 37, 1291-1297 (2016).

Srivastava, A.K., S.K. Chaturvedi and N.P. Singh: Genetic base of Indian chickpea (Cicer arietinum L) varieties revealed by pedigree analysis. Leg. Res., 40, 22-26 (2017).

Sunkad, G., H. Deepa, T.H. Shruthi and D. Singh: Chickpea wilt: Status, diagnostics and management. Indian Phytopathology, 72, 619$627(2019)$

Thudi, M., A. Chitikineni, X. Liu, W. He, M. Roorkiwal, W. Yang, J. Jian, D. Doddamani, P.M. Gaur, A. Rathore, S. Samineni, R.K. Saxena, D. Xu, N.P. Singh, S.K. Chaturvedi, G. Zhang, J. Wang, S.K. Datta, X. $X u$ and R.K. Varshney: Recent breeding programs enhanced genetic diversity in both desi and kabuli varieties of chickpea (Cicer arietinum L.). Sci. Rep., 6, 38636. doi:10.1038/srep38636. (2016).

Tullu, A., W.J. Kaiser, J.M. Kraft and F.J. Muehlbauer: A second gene for resistance to race 4 of Fusarium wilt in chickpea and linkage with a RAPD marker. Euphytica, 109, 43-50 (1999).

Yan, W.: Methodology of cultivar evaluation based on yield trial data-with special reference to winter wheat in Ontario. University of Guelph, Ontario, Canada (1999).

Yan, W.: Singular-value partitioning in biplot analysis of multienvironment trial data. Agronomy, 94, 990-996 (2002). 